\title{
Redistribution of substrates to adipose tissue promotes obesity in mice with selective insulin resistance in muscle
}

\author{
Jason K. Kim, ${ }^{1}$ M. Dodson Michael, ${ }^{2}$ Stephen F. Previs, ${ }^{1}$ \\ Odile D. Peroni, ${ }^{3}$ Franck Mauvais-Jarvis, ${ }^{2}$ Susanne Neschen, ${ }^{1}$ \\ Barbara B. Kahn, ${ }^{3}$ C. Ronald Kahn, ${ }^{2}$ and Gerald I. Shulman ${ }^{1}$ \\ ${ }^{1}$ Department of Internal Medicine and the Howard Hughes Medical Institute, Yale University School of Medicine, \\ New Haven, Connecticut, USA \\ ${ }_{2}^{2}$ Joslin Diabetes Center, and \\ ${ }^{3}$ Beth Israel Deaconess Medical Center, Department of Medicine, Harvard Medical School, Boston, Massachusetts, USA \\ Address correspondence to: Gerald I. Shulman, Howard Hughes Medical Institute, Yale University School of Medicine, \\ Boyer Center for Molecular Medicine, 295 Congress Avenue, BCMM 254C, Box 9812, New Haven, Connecticut 06536-8012, \\ USA. Phone: (203) 737-1115; Fax: (203) 737-4059; E-mail: gerald.shulman@yale.edu.
}

Received for publication August 31, 1999, and accepted in revised form May 9, 2000.

\begin{abstract}
Obesity and insulin resistance in skeletal muscle are two major factors in the pathogenesis of type 2 diabetes. Mice with muscle-specific inactivation of the insulin receptor gene (MIRKO) are normoglycemic but have increased fat mass. To identify the potential mechanism for this important association, we examined insulin action in specific tissues of MIRKO and control mice under hyperinsulinemic-euglycemic conditions. We found that insulin-stimulated muscle glucose transport and glycogen synthesis were decreased by about $80 \%$ in MIRKO mice, whereas insulin-stimulated fat glucose transport was increased threefold in MIRKO mice. These data demonstrate that selective insulin resistance in muscle promotes redistribution of substrates to adipose tissue thereby contributing to increased adiposity and development of the prediabetic syndrome.
\end{abstract}

J. Clin. Invest. 105:1791-1797 (2000).

\section{Introduction}

Insulin resistance is a major characteristic of various metabolic disorders, including type 2 diabetes mellitus and obesity $(1,2)$. It is well known that skeletal muscle is a major tissue responsible for insulinmediated glucose uptake $(3,4)$ and that defects in insulin-stimulated muscle glycogen synthesis are largely responsible for insulin resistance observed in patients with type 2 diabetes $(5,6)$. However, owing to multiple defects in insulin action in various insulin-resistant states, it has been difficult to determine the relative contribution of different insulinresponsive organs in the development of whole-body insulin resistance (7). Using the Cre-loxP-mediated recombination system with a muscle creatine kinase promoter, Bruning et al. (8) have developed mice with muscle-specific inactivation of the insulin receptor gene (muscle-specific insulin receptor knockout [MIRKO] mice) and demonstrated more than a 95\% decrease in muscle insulin receptors. Surprisingly, these mice displayed an increase in body fat and serum lipids, but normal glucose concentrations, despite a severe impairment in the insulin-signaling pathway in muscle (8). In this study, we conducted hyperinsulinemic-euglycemic clamps in MIRKO and control mice to assess insulin action in individual tissues and to examine the mechanism of compensation in this model of pure skeletal muscle insulin resistance.

\section{Methods}

Animals. Male MIRKO $(n=8)$ and control $(n=9)$ mice, in which exon 4 of the insulin receptor gene is flanked by lox sites [(IR $\left.{ }^{\text {lox/lox }}\right)$ mice], littermates weighing $20-25$ $\mathrm{g}(15-17$ weeks of age) were studied at least 7 days after arrival for stabilization in a new environment. Animals were housed under controlled temperature $\left(23^{\circ} \mathrm{C}\right)$ and lighting (12 hours of light: 0600-1800 hours; 12 hours of dark: $1800-0600$ hours) with free access to water and standard mouse chow. All procedures were approved by the Yale Animal Care and Use Committee.

Surgery and animal handling. At least 4 days before experiments, mice were anesthetized with an intramuscular injection of ketamine and xylazine $(10 \mathrm{mg} / 100 \mathrm{~g}$ body weight), and an indwelling catheter was inserted in the left internal jugular vein. The catheters were externalized through an incision in the skin flap behind its head, and the animals were returned to individual cages after the surgery. Mice fully recuperated from the surgery before in vivo experiments as reflected by them reaching preoperative weight. To conduct experiments in awake animals with minimal stress, a tail-restraint method was used during the experiments (9).

Hyperinsulinemic-englycemic clamp. Experiments were started at 0900 hours, after an overnight fast (food was removed at 1700 hours on the day before the experiment). A 120-minute hyperinsulinemic-euglycemic clamp was conducted with a continuous infusion of human insulin (Humulin; Novo Nordisk, Princeton, 
New Jersey, USA) at a rate of $15 \mathrm{pmol} / \mathrm{kg} / \mathrm{min}$ to raise plasma insulin within a physiological range. Blood samples $(20 \mu \mathrm{L})$ were collected at 20 - to 30 -minute intervals for the immediate measurement of plasma glucose concentration, and $20 \%$ glucose was infused at variable rates to maintain plasma glucose at basal concentrations. Insulin-stimulated whole-body glucose flux was estimated using a prime-continuous infusion of HPLCpurified [ $\left[{ }^{-3} \mathrm{H}\right]$ glucose $(10 \mu \mathrm{Ci}$ bolus, $0.1 \mu \mathrm{Ci} / \mathrm{min}$; NEN Life Science Products Inc., Boston, Massachusetts, USA) throughout the clamps. To estimate insulin-stimulated glucose transport activity in individual tissues, 2-deoxyD- $\left[1-{ }^{14} \mathrm{C}\right]$ glucose $\left(2-\left[{ }^{14} \mathrm{C}\right] \mathrm{DG}\right.$; NEN Life Science Products Inc.) was administered as a bolus $(10 \mu \mathrm{Ci})$ at 45 minutes before the end of clamps. Blood samples $(20 \mu \mathrm{L})$ were taken at 77, 80, 85, 90, 100,110, and 120 minutes after the start of clamps for the determination of plasma $\left[{ }^{3} \mathrm{H}\right]$ glucose, ${ }^{3} \mathrm{H}_{2} \mathrm{O}$, and $2-\left[{ }^{14} \mathrm{C}\right] \mathrm{DG}$ concentrations. Additional blood samples $(10 \mu \mathrm{L})$ were collected before the start and at the end of clamps for measurement of plasma insulin concentrations. All infusions were done using microdialysis pumps (CMA/Microdialysis, Acton, Massachusetts, USA). At the end of clamps, animals were anesthetized with sodium pentobarbital injection. Within 5 minutes, four muscles (soleus, gastrocnemius, tibialis anterior, and quadriceps) from both hindlimbs, epididymal adipose tissue, and liver were taken. Each tissue, once exposed, was dissected out within $2 \mathrm{sec}-$ onds, frozen immediately using liquid $\mathrm{N}_{2}$-cooled aluminum blocks, and stored at $-70^{\circ} \mathrm{C}$ for later analysis.

In vivo glucose flux analysis. Plasma glucose concentration during clamps was analyzed using $10 \mu \mathrm{L}$ plasma by a glucose oxidase method on a Beckman glucose analyzer II (Beckman Instruments Inc., Fullerton, California, USA). Plasma insulin concentration was measured by RIA using kits from Linco Research Inc. (St. Charles, Missouri, USA). For the determination of plasma $\left[3-{ }^{3} \mathrm{H}\right]$ glucose and $2-\left[{ }^{14} \mathrm{C}\right] \mathrm{DG}$ concentrations, plasma was deproteinized with $\mathrm{ZnSO}_{4}$ and $\mathrm{Ba}(\mathrm{OH})_{2}$, dried to remove ${ }^{3} \mathrm{H}_{2} \mathrm{O}$, resuspended in water, and counted in scintillation fluid (Ultima Gold; Packard, Meridien, Connecticut, USA) on dual channels for separation of ${ }^{3} \mathrm{H}$ and ${ }^{14} \mathrm{C}$. The plasma concentration of ${ }^{3} \mathrm{H}_{2} \mathrm{O}$ was determined by the difference between ${ }^{3} \mathrm{H}$ counts without and with drying. For the determination of tissue 2-[14C]DG-6phosphate (2-DG-6-P) content, tissue samples were homogenized, and the supernatants were subjected to an ion-exchange column to separate 2-DG-6-P from 2DG, as described previously (10). The radioactivity of ${ }^{3} \mathrm{H}$ in muscle glycogen was determined by digesting muscle samples in $\mathrm{KOH}$ and precipitating glycogen with ethanol as described previously (11). Skeletal muscle glycogen synthase activity was measured using ${ }^{14} \mathrm{C}$ UDPG.

Glucose transport and triglyceride synthesis in isolated adipocytes. Adipose cells were isolated from epididymal fat pads of additional control ( $n=4$ determinations) and MIRKO ( $n=5$ determinations) mice by collagenase digestion. For each determination, cells were pooled from three mice, making a total of 12 controls and 14 MIRKO mice. Cells were incubated in the absence (basal) or presence of varying concentrations of insulin, and the rates of in vitro glucose transport, glucose converted into triglyceride (i.e., triglyceride synthesis), lactate, and $\mathrm{CO}_{2}$ (i.e., glucose oxidation) were determined as described previously (12). The rates of in vitro glucose transport were measured using $3 \mu \mathrm{M}$ glucose, and glucose metabolic flux in isolated adipocytes were measured using $5 \mathrm{mM}$ glucose.

Calculations. Rates of whole-body glucose appearance and uptake were determined as the ratio of the $\left[{ }^{3} \mathrm{H}\right] \mathrm{glu}-$ cose infusion rate (disintegrations per minute/minute [dpm/min]) to the specific activity of plasma glucose $(\mathrm{dpm} / \mu \mathrm{mol})$ during the final 30 minutes of clamps. Hepatic glucose production during the hyperinsulinemic-euglycemic clamps was determined by subtracting the glucose infusion rate from the whole-body glucose appearance. Whole-body glycolysis was calculated from the rate of increase in plasma ${ }^{3} \mathrm{H}_{2} \mathrm{O}$ concentration, determined by linear regression of the measurements at 80 , $90,100,110$, and 120 minutes. Whole-body glycogen and lipid synthesis were estimated by subtracting wholebody glycolysis from whole-body glucose uptake, assuming that glycolysis and glycogen/lipid synthesis account for the majority of insulin-stimulated glucose uptake (13). Glucose transport activity in individual tissues was calculated from plasma $2-\left[{ }^{14} \mathrm{C}\right] \mathrm{DG}$ profile, which was fitted with a double exponential curve using MLAB (Civilized Software, Bethesda, Maryland, USA) and tissue 2DG-6-P content as described previously (14). Skeletal muscle glycogen synthesis was calculated from ${ }^{3} \mathrm{H}$ incorporation to muscle glycogen as described previously (14). Skeletal muscle glycolysis was then estimated as the difference between muscle glucose transport and muscle glycogen synthesis.

Table 1

Metabolic parameters during basal and hyperinsulinemic-euglycemic clamp periods in the control and MIRKO mice

\begin{tabular}{|c|c|c|c|c|c|c|c|c|}
\hline & \multicolumn{4}{|c|}{ Basal period } & \multicolumn{4}{|c|}{ Clamp period } \\
\hline & $\mathrm{n}$ & $\begin{array}{l}\text { Body } \\
\text { weight } \\
\text { (g) }\end{array}$ & $\begin{array}{l}\text { Plasma } \\
\text { glucose } \\
(\mathrm{mM})\end{array}$ & $\begin{array}{l}\text { Plasma } \\
\text { insulin } \\
(\mathrm{pM})\end{array}$ & $\begin{array}{l}\text { Plasma } \\
\text { glucose } \\
(\mathrm{mM})\end{array}$ & $\begin{array}{l}\text { Plasma } \\
\text { insulin } \\
(\mathrm{pM})\end{array}$ & $\begin{array}{c}\text { Glucose } \\
\text { infusion } \\
(\mu \mathrm{mol} / \mathrm{kg} / \mathrm{min})\end{array}$ & $\begin{array}{c}\mathrm{HGP} \\
(\mu \mathrm{mol} / \mathrm{kg} / \mathrm{min})\end{array}$ \\
\hline Control & 9 & $26 \pm 1$ & $6.3 \pm 0.3$ & $77 \pm 10$ & $6.2 \pm 0.1$ & $656 \pm 54$ & $205 \pm 6$ & $60 \pm 5$ \\
\hline MIRKO & 8 & $24 \pm 1$ & $6.5 \pm 0.3$ & $121 \pm 17^{A}$ & $6.3 \pm 0.2$ & $717 \pm 57$ & $79 \pm 10^{\mathrm{A}}$ & $67 \pm 7$ \\
\hline
\end{tabular}

${ }^{A} P<0.05$ versus control group by two-tailed $t$ test. HGP, hepatic glucose production. 

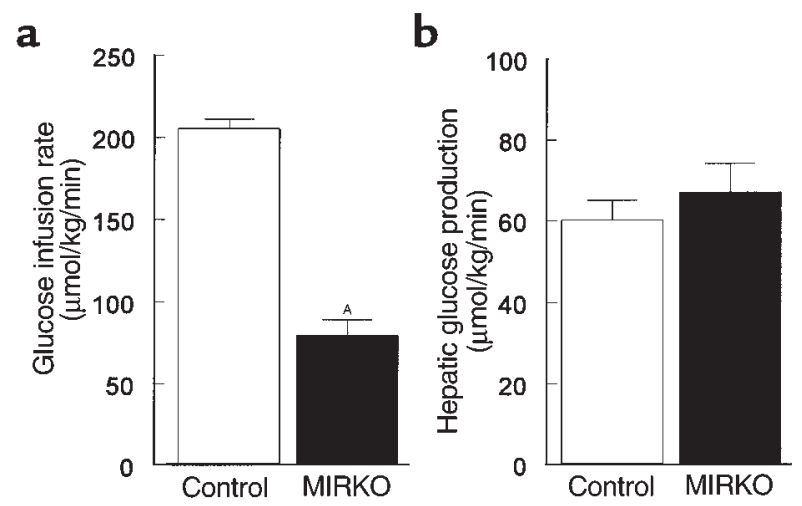

Figure 1

(a) Steady-state glucose infusion rate, obtained from averaged rates of 90-120 minutes of hyperinsulinemic-euglycemic clamps, in the control group and MIRKO group. (b) Hepatic glucose production during the insulin-stimulated state in the control group and MIRKO group. Values are means \pm SE for eight or nine experiments. ${ }^{A} P<0.05$ versus control group.

Statistical analysis. Data are expressed as means \pm SE. The significance of the difference in mean values between the control versus MIRKO group was evaluated using the unpaired $t$ test.

\section{Results}

The metabolic consequences of altering muscle insulin receptor content in MIRKO mice were examined during a 2-hour hyperinsulinemic-euglycemic clamp in awake MIRKO and control mice. Basal plasma insulin concentrations were increased by approximately $50 \%$ in the MIRKO mice compared with the controls $(P<0.05)$ (Table 1). During the clamps, plasma insulin concentrations were raised to approximately $700 \mathrm{pM}$, and plasma glucose was clamped at approximately 6.2 $\mathrm{mM}$ in both groups (Table 1 ). The rate of glucose infusion needed to maintain euglycemia increased rapidly in the control group and reached a steady state within 90 minutes. In contrast, there was a very blunted increase in glucose infusion rate in response to insulin in the MIRKO mice, resulting in a significant decrease in steady-state glucose infusion rate in the MIRKO mice (Figure 1a).

Insulin-stimulated whole-body glucose flux. Insulin-stimulated whole-body glucose uptake was decreased by $45 \%$ in the MIRKO mice $(146 \pm 12$ vs. $265 \pm 6$ $\mu \mathrm{mol} / \mathrm{kg} / \mathrm{min}$ in controls; $P<0.005$ ) (Figure 2a). Insulin-stimulated whole-body glycolysis was decreased by $25 \%$ in the MIRKO mice (135 \pm 11 vs. $178 \pm 9 \mu \mathrm{mol} / \mathrm{kg} / \mathrm{min}$ in controls; $P<0.005)$, but the most profound change was an $87 \%$ decrease in insulin-stimulated whole-body glycogen/lipid synthesis in the MIRKO mice $(11 \pm 4$ vs. $87 \pm 8$ $\mu \mathrm{mol} / \mathrm{kg} / \mathrm{min}$ in controls; $P<0.005$ ) (Figure $2 \mathrm{a}$ ). In contrast, insulin's ability to suppress hepatic glucose production (HGP) during clamps was not altered in the MIRKO mice (Figure 1b). Thus, these data indicate that reduced glucose requirement during the clamps was predominantly due to decreases in peripheral insulin action in the MIRKO mice.

Insulin-stimulated glucose transport activity in vivo in muscle and fat. Rates of insulin-stimulated glucose transport activity in individual tissues in vivo were estimated using 2-deoxy-D-[1-14C]glucose injection during hyperinsulinemic-euglycemic clamps in awake mice. Because 2-deoxyglucose is a glucose analog that is phosphorylated but not metabolized, insulin-stimulated glucose transport activity in individual tissues can be estimated by determining the tissue content of 2-deoxyglucose-6-phosphate. Insulin-stimulated glucose transport activity in skeletal muscle (gastrocnemius) was decreased by $74 \%$ in the MIRKO mice (57 \pm 11 vs. $219 \pm 23 \mathrm{nmol} / \mathrm{g} / \mathrm{min}$ in controls; $P<0.005)$ (Figure $2 \mathrm{~b}$ ). Although this decrease was similar to the pattern of changes observed in whole-body glucose uptake (Figure 2a), the decrease in insulin-stimulated muscle glucose transport was more profound than that in whole-body glucose uptake. Insulin-stimulated rates of glycolysis and glycogen synthesis in skele-

a

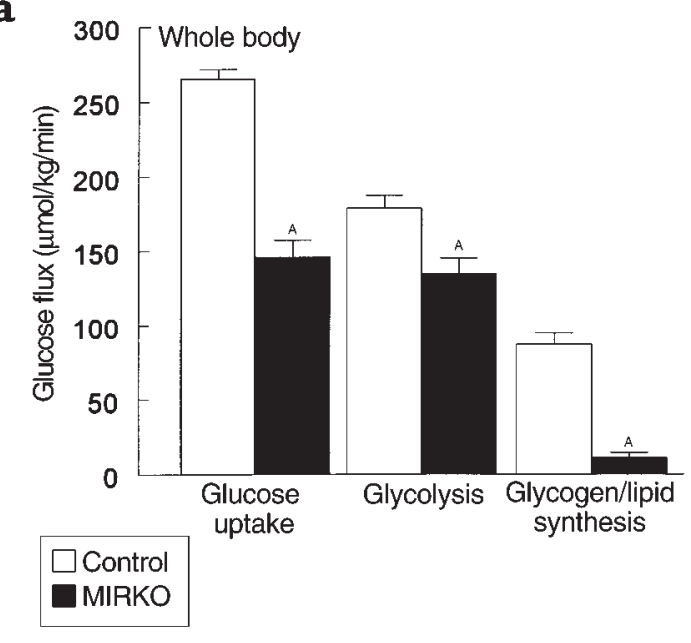

b

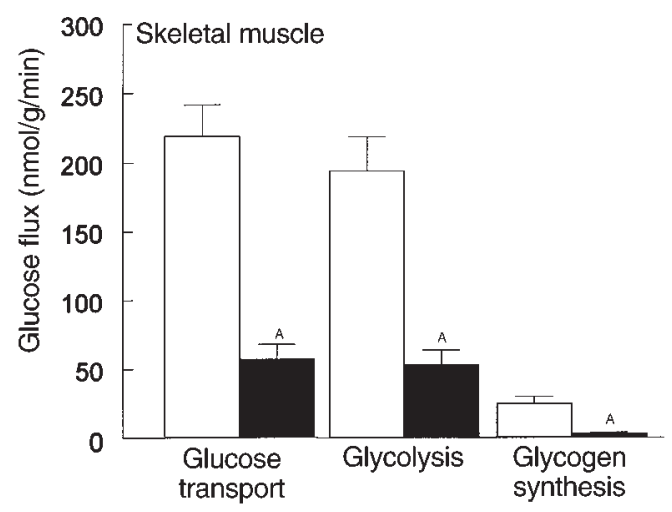

Figure 2

Whole-body and skeletal muscle glucose transport and metabolism. (a) Insulin-stimulated whole-body glucose uptake, glycolysis, and glycogen/lipid synthesis in vivo in the control group and MIRKO group. (b) Insulin-stimulated glucose transport, glycolysis, and glycogen synthesis in skeletal muscle (gastrocnemius) in vivo in the control group and MIRKO group. Values are means \pm SE for eight or nine experiments. ${ }^{A} P<0.005$ versus control group. 
a

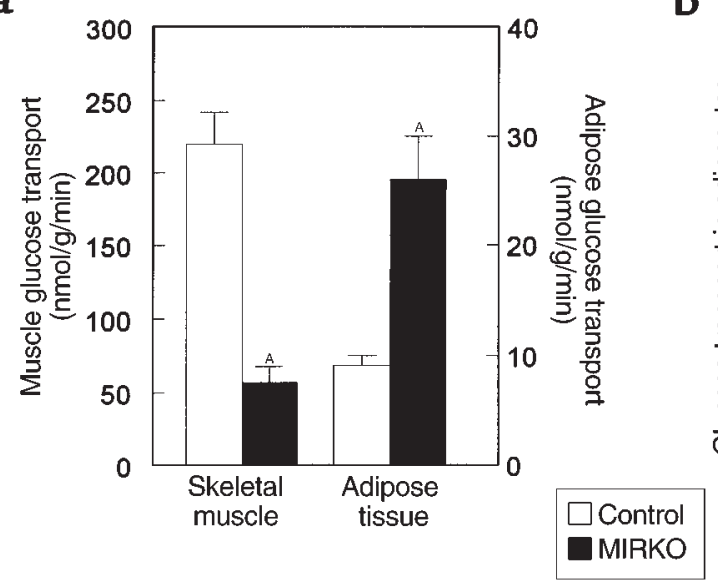

b

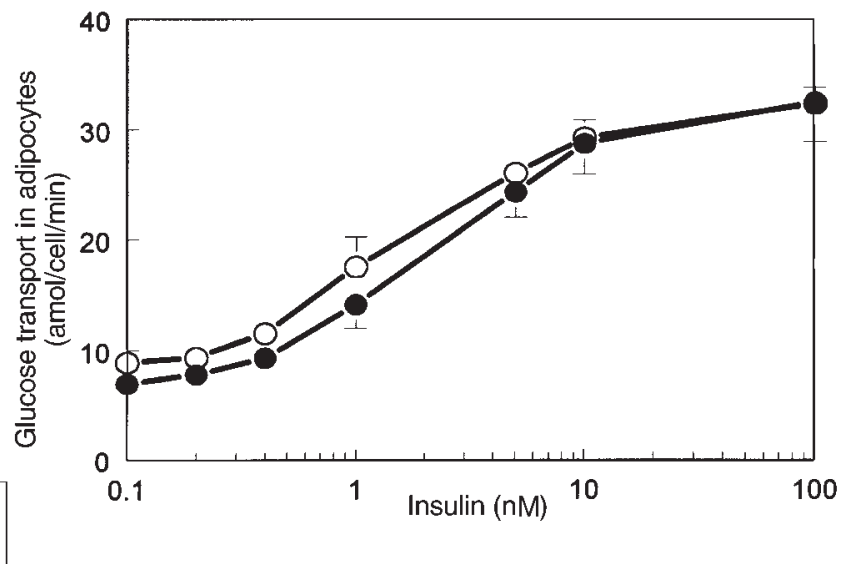

\section{Figure 3}

In vivo and in vitro glucose transport in adipose tissue. (a) Insulin-stimulated glucose transport in gastrocnemius muscle (left) and epididymal white adipose tissue (right) in vivo in the control group and MIRKO group. (b) Basal and insulin-stimulated glucose transport in isolated adipocytes in the control group and MIRKO group. Values are means \pm SE for four to nine experiments. ${ }^{A} P<0.005$ versus control group.

tal muscle were decreased by $73 \%$ and $88 \%$ (both $P<$ $0.005)$, respectively, in the MIRKO mice (Figure $2 \mathrm{~b}$ ). In contrast, insulin-stimulated glucose transport activity in epididymal white adipose tissue was significantly increased threefold in the MIRKO mice (26士 4 vs. $9 \pm 1 \mathrm{nmol} / \mathrm{g} / \mathrm{min}$ in controls; $P<0.005$ ) (Figure $3 a)$. These findings indicate that decreases in insulinstimulated muscle glucose transport were partly compensated for by increases in insulin-stimulated glucose transport activity in adipose tissue. Total GLUT4 content in skeletal muscle (quadriceps) was not altered in the MIRKO mice compared with the control mice. Similarly, total GLUT4 and GLUT1 contents in epididymal white adipose tissue were not altered in the MIRKO mice.

Glycogen synthase activity in skeletal muscle. Insulinstimulated activation of glycogen synthase was significantly decreased by $43 \%$ in the MIRKO mice ( $23 \pm$ 5 vs. $40 \pm 6 \%$ activation in controls; $P<0.05)$. The decrease in insulin-stimulated muscle glycogen synthesis in the MIRKO mice could largely be attributed to reduced insulin-stimulated activation of muscle glycogen synthase.

In vitro glucose transport and triglyceride synthesis in isolated adipocytes. Rates of basal and insulin-stimulated glucose transport in isolated adipocytes were not altered in the MIRKO mice compared with the con- trol mice (Figure 3b). Furthermore, rates of basal and insulin-stimulated conversion of glucose into lactate or triglyceride (i.e., triglyceride synthesis) in isolated adipocytes were not altered in the MIRKO mice compared with the control mice (Figure 4, a and $b$ ). However, rates of basal and insulin-stimulated conversion of glucose into $\mathrm{CO}_{2}$ (i.e., glucose oxidation) were decreased in the MIRKO mice $(P<0.05$ for both) (Figure 4c).

Changes in whole-body composition. Plasma triglyceride and FFA concentrations were elevated by $43 \%$ (165 \pm 14 vs. $116 \pm 13 \mathrm{mg} / \mathrm{dL}$ in controls; $P<0.05$ ) and $16 \%$ $(1.59 \pm 0.06$ vs. $1.38 \pm 0.06 \mathrm{mM}$ in controls; $P<0.05)$, respectively, in the MIRKO mice. Mass of quadriceps/gastrocnemius, soleus, extensor digitorum longus, and heart muscles were decreased by $13 \%$, $27 \%, 15 \%$, and $28 \%$, respectively, in the MIRKO mice ( $P<0.05$ for all of the muscles) (Table 2). In contrast, whole-body fat pad mass was increased by $38 \%$ in the MIRKO mice $(P<0.01)$ (Table 2).

\section{Discussion}

Joshi et al. (15) and Accili et al. (16) have previously shown that mice lacking insulin receptors in all tissues, via targeted disruption of insulin receptor gene, had marked hyperglycemia, and died within the first week of life. In contrast MIRKO mice, with muscle

Table 2

Body composition in the control and MIRKO mice

\begin{tabular}{|c|c|c|c|c|c|c|}
\hline & \multicolumn{6}{|c|}{ Tissue mass } \\
\hline & $n$ & $\begin{array}{c}\text { Gastrocnemius and } \\
\text { quadriceps muscles } \\
\text { (mg) }\end{array}$ & $\begin{array}{l}\text { Soleus } \\
\text { muscle } \\
(\mathrm{mg})\end{array}$ & $\begin{array}{l}\text { EDL } \\
\text { muscle } \\
(\mathrm{mg})\end{array}$ & $\begin{array}{l}\text { Heart } \\
\text { muscle } \\
(\mathrm{mg})\end{array}$ & $\begin{array}{l}\text { Whole body } \\
\text { fat pad } \\
\text { (\% of BW) }\end{array}$ \\
\hline Control & 7 & $608 \pm 12$ & $7.4 \pm 0.2$ & $9.9 \pm 0.2$ & $171 \pm 4$ & $27.5 \pm 2.3$ \\
\hline MIRKO & 8 & $528 \pm 11^{A}$ & $5.4 \pm 0.1^{\mathrm{A}}$ & $8.4 \pm 0.1^{\mathrm{A}}$ & $123 \pm 7^{A}$ & $38.0 \pm 6.4^{\mathrm{A}}$ \\
\hline
\end{tabular}

A $P<0.05$ versus control group by two-tailed $t$ test. EDL, extensor digitorum longus; BW, body weight. 
specific inactivation of the insulin receptor gene, have normal plasma glucose concentrations (8) despite significant decreases in insulin-stimulated whole body and skeletal muscle glucose transport activity. Previous studies have shown that decreases in muscle insulin receptor content in MIRKO mice virtually abolished insulin-stimulated tyrosine phosphorylation of insulin receptor and IRS-1 in skeletal muscle (8). The phosphorylation of IRS-1 and subsequent activation of phosphatidylinositol 3-kinase (PI 3-kinase) have been associated with insulin's action to stimulate glucose transport in muscle. Immediately after insulin injection in mice, there are 10- to 20 -fold increase in activation of PI 3-kinase (17) and increased translocation of glucose transporters (i.e., GLUT4) from an intracellular pool to the plasma membrane (18). In the present study, transgenic mice with muscle-specific inactivation of insulin receptor gene exhibited a significant decrease in in vivo insulin-stimulated glucose transport activity in skeletal muscle. These results further support the important role of insulin receptor and phosphorylation of insulin signaling substrates (e.g., IRS-1 and IRS-2) in insulin's effect on glucose transport in muscle (19, 20). Overall, decreases in insulin-stimulated phosphorylation of IRS- 1 and activation of IRS- 1 associated PI 3-kinase, both resulting from reduced muscle insulin receptor content, are presumably responsible for reduced insulin-stimulated skeletal muscle glucose transport activity in the MIRKO mice. In addition to altered glucose transport activity, insulinstimulated glucose metabolic flux (i.e., glycolysis and glycogen synthesis) in skeletal muscle were similarly reduced in the MIRKO mice. Glucose transport is considered to be rate-controlling for glucose utilization in skeletal muscles (21-24), and decreases in insulin-stimulated muscle glucose transport activity may account for the parallel decreases in glycolysis and glycogen synthesis in the MIRKO mice. Howev$\mathrm{er}$, it is interesting to note that the decrease in insulin-stimulated muscle glycogen synthesis was more severe than the decrease in muscle glucose transport activity. This may be accounted for by additional defects in insulin's activation of glycogen synthase activity as observed in the MIRKO mice.

Despite the severe decrease in insulin-stimulated glucose transport activity in skeletal muscles, it was surprising to find a relatively mild whole-body insulin resistant state in the MIRKO mice. Furthermore, despite markedly reduced insulin-stimulated muscle glucose transport, the MIRKO mice had normal fasting and postprandial glucose concentrations (8). These findings suggest the existence of compensatory mechanism(s) in the MIRKO mice, which counter the severe defects in insulin-stimulated muscle glucose disposal. It has been speculated that increases in IGF1 receptors might compensate for the lack of insulin receptors in the MIRKO mice; however, there was neither a difference in the expression of IGF-1 receptor nor detectable insulin-stimulated IGF-1 receptor tyrosine phosphorylation in skeletal muscle of MIRKO and control (i.e., IR $\mathrm{I}^{\text {lox/lox }}$ and wild-type) mice (8). In the present study, we examined insulin action in white adipose tissue and found that white adipose tissue, in

\section{$\mathbf{a}$}

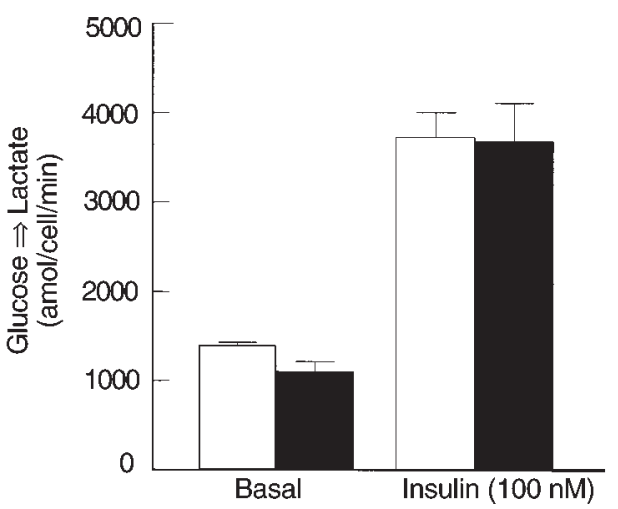

b

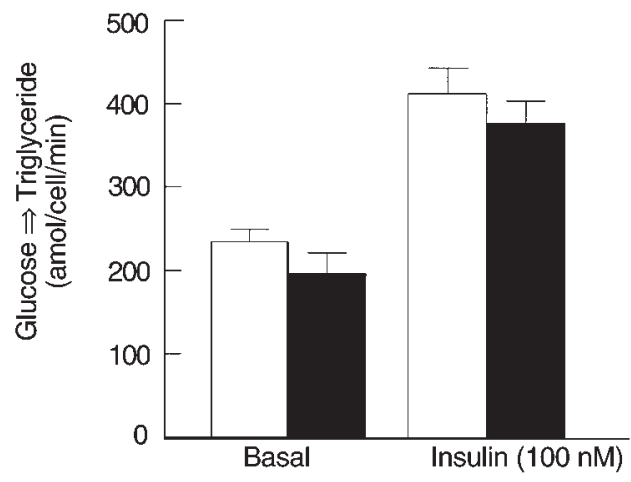

C

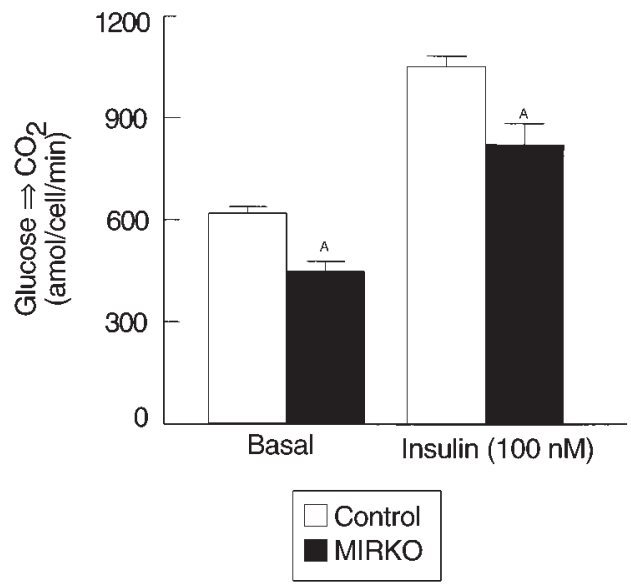

\section{Figure 4}

Glucose metabolic flux in isolated adipocytes. (a) Basal (left) and insulin-stimulated (right) conversion of glucose into lactate in isolated adipocytes in the control group and MIRKO group. (b) Basal (left) and insulin-stimulated (right) conversion of glucose into triglyceride in isolated adipocytes in the control group and MIRKO group. (c) Basal (left) and insulin-stimulated (right) conversion of glucose into $\mathrm{CO}_{2}$ in isolated adipocytes in the control group and MIRKO group. Values are means \pm SE for four or five experiments. ${ }^{A} P<0.05$ versus control group. 
the presence of decreased muscle insulin receptor content, partly compensates for reduced muscle glucose transport activity by increasing glucose transport into white adipose tissue. In other words, in the presence of markedly reduced insulin action in skeletal muscle, glucose was partly shunted to the white adipose tissue. This compensatory increase in glucose transport in white adipose tissue and possibly other insulin-sensitive organs (e.g., brown adipose tissue, liver) may explain the relatively mild whole-body insulin resistance despite a significant decrease in insulin-stimulated muscle glucose transport in the MIRKO mice. In contrast to these in vivo findings, insulin-stimulated glucose transport and triglyceride synthesis in isolated adipocytes were not altered in the MIRKO mice. Thus, our observation of increased insulin-stimulated glucose transport in white adipose tissue and increased fat mass may involve in vivo specific factors.

We measured the total GLUT4 content in skeletal muscle (quadriceps) and GLUT4 and GLUT1 contents in epididymal adipose tissue and found that the total GLUT4 and GLUT1 contents were not altered in these tissues obtained from the MIRKO mice. This finding suggests that the defect in insulin-stimulated muscle glucose transport may be due to impaired insulin-stimulated translocation of GLUT4 from the intracellular pool to the plasma membrane in the MIRKO mice. Similarly, increased insulin-stimulated fat glucose transport may be due to increased translocation of GLUT4 from the intracellular pool to the plasma membrane in response to insulin in the MIRKO mice. In various metabolic states, changes in insulin-stimulated glucose transport activity have been more closely associated with a reduction in insulin-stimulated GLUT4 translocation than to alteration in total GLUT4 content (25-27). Despite a significant decrease in insulin-stimulated muscle glucose transport in obese and type 2 diabetes subjects $(25,26)$, Pedersen et al. (27) failed to demonstrate alterations in the total level of GLUT4 in the vastus lateralis muscle of type 2 diabetes subjects.

The divergent regulation of in vivo glucose transport by skeletal muscle and adipose tissue has been previously observed in various metabolic states. Cusin et al. $(28,29)$ have shown that chronic hyperinsulinemia decreased insulin-stimulated muscle glucose transport, whereas it increased levels of GLUT4 and insulin-stimulated glucose transport in adipose tissue in rats. Cusin et al. have speculated that hyperinsulinemia might account for increased insulin-stimulated adipose tissue glucose transport (29), and it is possible that the mild degree of hyperinsulinemia observed in the MIRKO mice contributed to the upregulation of insulin action on GLUT4 translocation in adipose tissue by this mechanism. It is also possible that either a substrate or humoral factor(s) released by skeletal muscle leads to some upregulation of adipose tissue in response to insulin at some sites between the insulin receptor and GLUT4 protein.
In summary, selective inactivation of muscle insulin receptor gene resulted in decreased insulin-stimulated glucose transport into skeletal muscle that was partly compensated for by increases in adipose tissue glucose transport activity. These findings demonstrate that selective insulin resistance in muscle promotes redistribution of substrates to adipose tissue, thereby contributing to increased adiposity and development of the prediabetic syndrome.

\section{Acknowledgments}

This study was supported by grants from the United States Public Health Service (R01 DK 40936 and P30 DK 45735 to G.I. Shulman; R01 DK 43051 to B.B. Kahn; and R01 DK 33201 to C.R. Kahn). J.K. Kim is a research associate and G.I. Shulman is an Investigator of the Howard Hughes Medical Institute. We are grateful to P. McNulty, Y. Zhu, V. Walton, and A. Groszmann for technical assistance. We are also grateful to J.F.P. Wojtaszewski and L. Goodyear for providing us the tissue mass data shown in Table 2.

1. DeFronzo, R.A., Simonson, D., and Ferrannini, E. 1982. Hepatic and peripheral insulin resistance: a common feature of type 2 (noninsulin-dependent) and type 1 (insulin-dependent) diabetes mellitus. Diabetologia. 23:313-319.

2. Hollenbeck, C.B., Chen, Y.I., and Reaven, G.M. 1984. A comparison of the relative effects of obesity and non-insulin-dependent diabetes mellitus on in vivo insulin-stimulated glucose utilization. Diabetes. 33:622-626.

3. Shulman, G.I., et al. 1990. Quantitation of muscle glycogen synthesis in normal subjects and subjects with non-insulin-dependent diabetes by ${ }^{13} \mathrm{C}$ nuclear magnetic resonance spectroscopy. N. Engl. J. Med. 322:223-228.

4. DeFronzo, R.A., et al. 1981. The effect of insulin on the disposal of intravenous glucose. Results from indirect calorimetry and hepatic and femoral venous catheterization. Diabetes. 30:1000-1007.

5. Beck-Nielsen, H., et al. 1992. Insulin resistance in skeletal muscles in patients with NIDDM. Diabetes Care. 15:418-429.

6. Bogardus, C., and Lillioja, S. 1990. Where all the glucose doesn't go in non-insulin-dependent diabetes mellitus. N. Engl. J. Med. 322:262-263.

7. Kahn, C.R. 1994. Banting Lecture. Insulin action, diabetogenes, and the cause of type II diabetes. Diabetes. 43:1066-1084.

8. Bruning, J.C., et al. 1998. A muscle-specific insulin receptor knockout exhibits features of the metabolic syndrome of NIDDM without altering glucose tolerance. Mol. Cell. 2:559-569.

9. Kim, J.K., Gavrilova, O., Chen, Y., Reitman, M.L., and Shulman, G.I. 2000. Mechanism of insulin resistance in A-ZIP/F-1 fatless mice. J. Biol. Chem. 275:8456-8460.

10. Ohshima, K., Shargill, N.S., Chan, T.M., and Bray, G.A. 1984. Adrenalectomy reverses insulin resistance in muscle from obese (ob/ob) mice. Am. J. Physiol. 246:E193-E197.

11. Kim, J.K., Wi, J.K., and Youn, J.H. 1996. Plasma free fatty acids decrease insulin-stimulated skeletal muscle glucose uptake by suppressing glycolysis in conscious rats. Diabetes. 45:446-453.

12. Tozzo, E., Shepherd, P.R., Gnudi, L., and Kahn, B.B. 1995. Transgenic GLUT-4 overexpression in fat enhances glucose metabolism: preferential effect on fatty acid synthesis. Am. J. Physiol. 268:956-964.

13. Rossetti, L., and Giaccari, A. 1990. Relative contribution of glycogen synthesis and glycolysis to insulin-mediated glucose uptake. J. Clin. Invest. 85:1785-1792.

14. Youn, J.H., and Buchanan, T.A. 1993. Fasting does not impair insulin-stimulated glucose uptake but alters intracellular glucose metabolism in conscious rats. Diabetes. 42:757-763.

15. Joshi, R.L., et al. 1996. Targeted disruption of the insulin receptor gene in the mouse results in neonatal lethality. EMBO J. 15:1542-1547.

16. Accili, D., et al. 1996. Early neonatal death in mice homozygous for a null allele of the insulin receptor gene. Nat. Genet. 12:106-109.

17. Folli, F., Saad, M.J.A., Backer, J.M., and Kahn, C.R. 1992. Insulin stimulation of phosphatidylinositol 3-kinase activity and association with IRS-1 in liver and muscle of the intact rat. J. Biol. Chem. 267:22171-22177. 
18. Marette, A., Burdett, E., Douen, A., Vranic, M., and Klip, A. 1992. Insulin induces the translocation of GLUT4 from a unique intracellular organelle to transverse tubules in rat skeletal muscle. Diabetes. 41:1562-1569.

19. Le Marchand-Brustel, Y. 1999. Molecular mechanisms of insulin action in normal and insulin-resistant states. Exp. Clin. Endocrinol. Diabetes. 107:126-132.

20. Jullien, D., Heydrick, S.J., Gautier, N., Van Obberghen, E., and Le Marchand-Brustel, Y. 1996. Effect of IGF-I on phosphatidylinositol 3-kinase in soleus muscle of lean and insulin-resistant obese mice. Diabetes. 45:869-875.

21. Ren, J.-M., et al. 1993. Evidence from transgenic mice that glucose transport is rate-limiting for glycogen deposition and glycolysis in skeletal muscle. J. Biol. Chem. 268:16113-16115.

22. Cline, G.W., et al. 1999. Impaired glucose transport as a cause of decreased insulin-stimulated muscle glycogen synthesis in type 2 diabetes. N. Engl. J. Med. 341:240-246.

23. Goodman, M.N., Berger, M., and Ruderman, N.B. 1974. Glucose metabolism in rat skeletal muscle at rest. Effect of starvation, diabetes, ketone bodies, and free fatty acids. Diabetes. 23:881-888.
24. Richter, E.A., Garetto, L.P., Goodman, M.N., and Ruderman, N.B. 1982. Muscle glucose metabolism following exercise in the rat: increased sensitivity to insulin. J. Clin. Invest. 69:785-793.

25. Garvey, W.T., Huecksteadt, T.P., Matthaei, S., and Olefsky, J.M. 1988. Role of glucose transporters in the cellular insulin resistance of type II non-insulin-dependent diabetes mellitus. J. Clin. Invest. 81:1528-1536.

26. Garvey, W.T. 1992. Glucose transport and NIDDM. Diabetes Care. 15:396-417.

27. Pedersen, O., et al. 1990. Evidence against altered expression of GLUT1 or GLUT4 in skeletal muscle of patients with obesity or NIDDM. Diabetes. 39:865-870.

28. Cusin, I., Terrettaz, J., Rohner-Jeanrenaud, F., and Jeanrenaud, B. 1990. Metabolic consequences of hyperinsulinemia imposed on normal rats on glucose handling by white adipose tissue, muscles, and liver. Biochem. J. 267:99-103

29. Cusin, I., et al. 1990. Hyperinsulinemia increases the amount of GLUT4 mRNA in white adipose tissue and decreases that of muscles, a clue for increased fat depot and insulin resistance. Endocrinology. 127:3246-3248. 